University of South Florida

DIGITAL COMMONS

Digital Commons @ University of

@ UNIVERSITY OF SOUTH FLORIDA

South Florida

QMaSC: A Handbook for Directors of

Quantitative and Mathematics Support Centers

USF Libraries

$1-1-2016$

\title{
18. Center Staff Feedback
}

Dennis Lewandowski

Michigan Technological University

Follow this and additional works at: https://digitalcommons.usf.edu/qmasc_handbook

\section{Recommended Citation}

Dennis Lewandowski (2016), "Center Staff Feedback", http://dx.doi.org/10.5038/9780977674435.ch18 in G. Coulombe, M. O'Neill, M. Schuckers (Eds.) A Handbook for Directors of Quantitative and Mathematical Support Centers, Neck Quill Press, http://scholarcommons.usf.edu/qmasc_handbook.

This Center Assessment is brought to you for free and open access by the USF Libraries at Digital Commons @ University of South Florida. It has been accepted for inclusion in QMaSC: A Handbook for Directors of Quantitative and Mathematics Support Centers by an authorized administrator of Digital Commons @ University of South Florida. For more information, please contact digitalcommons@usf.edu. 


\section{Center Staff Feedback}

(C) Dennis Lewandowski,

Michigan Technological University

प्र

\section{Communication Between Director and Staff}

\section{Staff to Director Feedback}

The tutors of the QMaSC have the most direct contact between the student-clients and the learning center organization. Thus they are in the position to understand what is working and what is not. It is important for the director of the center to have a system in place that can glean this information from the staff of the center. Three systems are commonly in use: regular written evaluations of the center's operations, open staff meetings where all aspects of the center are fair game for discussion, and a combination of the two.

With regular written evaluations, simple one-page, four-question forms of this type should be sufficient to encourage reflection upon the operations of the center:

a What do you like best about the center?

b What things about the center would you like to change?

c What are the center's strengths?

d What are the center's weaknesses?

The evaluations may be printed on paper or available online (e. g. as a Google form), and the evaluations may be collected on a regular basis (weekly or monthly) or once each semester (mid-semester assessment or end of semester). Since the QMaSC staff is commonly composed of

Suggested Citation: Dennis Lewandowski (2016), "Center Staff Feedback", http://dx.doi.org/10.5038/ 9780977674435.ch18 in G. Coulombe, M. O'Neill, M. Schuckers (Eds.) A Handbook for Directors of Quantitative and Mathematical Support Centers, Neck Quill Press, http://scholarcommons.usf.edu/qmasc_handbook.

This material is based upon work supported, in part, by the National Science Foundation under Grant DUE1255945. Any opinions, findings, and conclusions or recommendations expressed in this material are those of the author(s) and do not necessarily reflect the views of the National Science Foundation 
students who have recently taken the course(s) being tutored, the composition of the staff changes quite often. It ordinarily takes eight weeks or so for new tutors to start feeling comfortable enough with processes to be able to offer feedback.

Open staff meetings where the entire staff of the center is present and can discuss everything openly can be useful both for identifying strengths and weaknesses of the center and for brainstorming solutions to issues. The director of the center must be able to accept all input and be open to discussion, and the director should be prepared to ask open questions that can lead to successful group problem solving. Obtaining staff input about solutions also helps increase the likelihood that the staff will take ownership of new procedures and policies.

If both written evaluations and open staff meeting are used as feedback mechanisms, the results of regular written evaluations can be used as the starting point of the staff meeting discussions, possibly improving the efficiency of the staff meeting. Additionally, staff members should be encouraged to speak privately to the director about any matter as it arises. These individual conversations can help identify topics to discuss at staff meetings, too.

\section{Director to Staff Feedback}

In an ideal world, the feedback from the center director to the staff would consist of an individual evaluation of each tutor's job performance. This is sometimes difficult because of several factors:

- The high turnover rate of tutors.

- The high turnover rate of student-clients.

- The lack of a consistent tutor-to-student pairing for more than one academic term

- The constraints on the learning center director's time that may make individual evaluation of each tutor's performance problematic at best.

However, at the very least, a director should be alert for indications of the quality of the tutors' work, such as comments, compliments, and complaints from student clients.

One feedback mechanism is the student-client evaluation of each individual tutor. This is a standard evaluation given near the end of the academic term that attempts to gauge the tutor's job performance. This type of evaluation is most helpful when the client has had a standing appointment with the same tutor throughout the academic term. It is less useful, but still appropriate, for a drop-in tutoring center. The director can use the results of these evaluations when judging the effectiveness of the tutors.

Ultimately, the QMaSC director must use the overall operation of the center as the best feedback tool to and from the staff. The number of visits to the center is the best gauge of center operations. If the number of visits rises from one term to the next, it is a strong indication that students are satisfied with the services they have received and that the center is a welcoming place. 


\section{Incorporating staff input into management decisions}

The use of staff input in management decisions works best if the following principles are observed:

1. Hire very good staff. The hiring process must be rigorous and thorough.

2. Clearly communicate operational rules to the tutors.

3. Give the staff the learning tools they need.

4. Treat the staff as colleagues more than employees.

5. Let them do their jobs.

\section{Conclusion}

All of the feedback between the learning center director and the staff is most meaningful if it results in some visible change to the center's operation. The change must be visible to the tutors, the student-clients, the director of the center, and the academic administration. By spelling out the steps tutors can take in order to communicate with each other, and with the director, open and honest dialogue can take place, thus enhancing the ability for all constituents to focus on a positive tutoring process and on preparation of the tutors. 